\section{Acetic Acid Fumigation of Fruit Storage Bins to Control Diapausing Codling Moth Larvae}

\author{
Paul Randall, Peter Sholberg, Gary Judd, and Joan Cossentine ${ }^{1}$
} Agriculture and Agri-Food Canada, Pacific Agri-Food Research Centre, 4200 Highway 97, Box 5000, Summerland, British Columbia V0H 1Z0, Canada

Additional index words. Cydia pomonella, bin sanitation, bin type

\begin{abstract}
Fumigation with glacial acetic acid (AA) vapor successfully kills post-harvest pathogens on tree fruits and berries and reduces their spoilage in storage. In this study, we investigated whether a similar approach could be implemented to eradicate diapausing larvae of the codling moth, Cydia pomonella (L.), from fruit harvest bins they commonly infest. In 24-h tests conducted in $\mathbf{0 . 0 2 3}-\mathrm{m}^{3}$ fumigation chambers using two concentrations of vaporized AA [117,360 and 174,823 cumulative parts per million-hours (ppm-h)], mortality of diapausing larvae was $81 \%$ and $100 \%$, respectively. A similar 24-h exposure to a 61,940 cumulative ppm-h treatment of AA caused no mortality. A 24-h fumigation of diapausing codling moth larvae placed in scaled-down plastic fruit bins treated with $55 \mathrm{~mL}$ of AA evaporated into a $1-\mathrm{m}^{3}$ chamber caused $100 \%$ mortality. The same fumigation treatment of artificially infested, scaled-down wooden fruit bins caused no significant mortality of test larvae. Atmospheric concentrations of AA vapor in $1-\mathrm{m}^{3}$ fumigation chambers containing wooden bins could not be maintained at levels necessary to cause insect death, even after multiple injections of AA. We hypothesize that either the wood or the moisture contained therein absorbs or in some other way interacts with the $A A$ vapor. The use of $\mathrm{AA}$ as a fumigant targeting codling moth larvae in wooden bins is not practical or economical at this time. Fumigation of plastic fruit bins with AA would provide an economical and environmentally friendly method of killing diapausing codling moth larvae. The successful disinfestations of plastic fruit bins of codling moth would prevent these bins from being an external source of infestation, thereby decreasing overall codling moth infestation in orchards, which in turn benefits current densitydependent management practices used for the area-wide control of codling moth. chemical name: Glacial Acetic Acid (AA).
\end{abstract}

Codling moth, Cydia pomonella L. (Lepidoptera: Tortricidae), is a key pest of pome fruits worldwide. This insect overwinters as a diapausing, fifth-instar larva located within a silken cocoon usually constructed in cracks or crevices of bark on host apple and pear trees. In most temperate pome-fruit production regions, codling moth larvae destined for diapause exit host fruit in late summer and early fall and wander in search of overwintering sites. While doing this, the diapause-destined larvae frequently encounter and infest fruit bins that are placed in the orchards before harvest (Higbee et al., 1999). Bins with harvested fruit are moved to packing houses where they are emptied and stored outdoors before being redistributed to orchards the next season. Bins that are inadvertently infested with diapausing larvae become unpredictable sources of adult codling moth that can significantly impact orchard pest management programs. In particular, these external sources of wild codling moth are problematic for orchardists relying on sterile insect release programs or pheromone-based mating disruption because

Received for publication 15 July 2011. Accepted for publication 4 Oct. 2011.

${ }^{1}$ To whom reprint requests should be addressed; e-mail joan.cossentine@agr.gc.ca.
2009). AA is also a relatively inexpensive and naturally occurring compound that poses little or no hazard to human health when used at the very low concentrations required to kill fungal spores. For example, Sholberg and Gaunce (1995) showed that AA concentrations of 2 to $4.7 \mathrm{mg} \cdot \mathrm{L}^{-1}$ were extremely effective at killing conidia of Botrytis cinerea [Fuckeliana (de Bary) Fuckel] or Pencillium expansum Link on apples without causing any phytotoxic effects. AA vapor has also been used to protect grapes and strawberries (Moyls et al., 1996), stone fruits (Sholberg and Gaunce, 1996), and 'd'Anjou' pears (Sholberg et al., 2004) from fungal rots that cause spoilage in storage. Other studies have indicated that AA vapor will eliminate powdery mildew infections of apple buds, eliminate Erwinia amylovora [(Burrill) Winslow] and Pseudomonas syringae pv. syringae (van Hall) as surface contaminants of dormant scion wood (Sholberg et al., 2005), and even control common bunt of wheat (Sholberg et al., 2006).

The goals of this study were 1) to determine whether AA could be used as a fumigant to kill wild diapausing codling moth larvae; and 2) to compare the efficacy of a fumigation treatment when applied to scaleddown fruit harvest bins made of plastic or wood.

\section{Materials and Methods}

\section{Insects}

In June 2008, corrugated cardboard strips were wrapped around tree trunks in an infested apple orchard as described by Judd et al. (1997). Wild, diapause-destined codling moth larvae exited infested fruit and spun cocoons inside these cardboard strips. Cardboard was removed from trees in Oct. 2008, placed in plastic garbage bags, and held in an outdoor screenhouse through winter. In Spring 2009, a subset of these diapausing larvae was transferred to the Pacific AgriFood Research Center, Summerland, British Columbia, Canada, where they were stored in complete darkness at $2{ }^{\circ} \mathrm{C}$ until needed for experiments. When needed for experiments, the cardboard backing surrounding each singular cocooned larva was cut from the larger strip with fine scissors so as to leave the cocoon attached to a small amount of cardboard and the larva undisturbed in its cocoon. All test larvae were stored like this at $2{ }^{\circ} \mathrm{C}$ for up to 2 weeks before receiving fumigation treatments.

\section{Fumigation chambers}

Two different types of custom-made fumigation chambers were used for these experiments. The first fumigation chamber was a modification of the one described in detail by Sholberg et al. (2000). This modified chamber consisted of a $23-\mathrm{L}\left(0.023 \mathrm{~m}^{3}\right)$ heavy duty aluminum cooking pot and lid (Russell Food Equipment, Vancouver, BC, Canada). The underside lip of each lid was fitted with a rubber seal. Four, hooked draw latches (Southco, Concordville, PA) were attached on the outside of the pot and evenly spaced to ensure an 
airtight seal. An evaporator was made from an aluminum rod $(25 \mathrm{~mm}$ diameter $\times 75 \mathrm{~mm}$ length) that had a hole drilled in one end to allow fitting of a 9.5 -mm-diameter $150-\mathrm{W}$ cartridge heater (CIR No. 2012/120; Omega Engineering, Stamford, CT). A 40-mm long groove large enough to hold $3 \mathrm{~mL}$ of water or AA was milled on the top of the rod. The evaporator was attached to the underside of the chamber lid. Liquids were placed in the evaporator using a $250-\mu \mathrm{L}$ Hamilton glass syringe (Hamilton, Reno, NV) inserted through a hole drilled into the clear polycarbonate viewing port on the top of the lid. Placement and evaporation of all liquids and functioning of the evaporator were observed through the viewing port. During each experiment, all of the liquid boiled off in less than 2 min of operation with very little release of heat into the chamber (Sholberg et al., 2000). During evaporation of all liquids, a 75-mm tube axial fan (Papst Typ 8300N, 115 V 50 to $60 \mathrm{~Hz} 12 \mathrm{~W}$; Papst Motoren Gmbn. and Co., Georgen, Germany), also attached to the inner side of the lid, was in operation throughout the fumigation.

The second fumigation chamber was a $1-\mathrm{m}^{3}$ wooden chamber described by Gaunce et al. (1981). This chamber was modified from its original design when the interior surfaces were covered with $0.3 \mathrm{~mm}$ of aluminum flashing and all seams and exposed wood were covered with aluminum foil tape (Home Hardware, Penticton, BC, Canada). The fumigation chamber had a removable front, which enabled the placement of scalesized bins inside. The edges of the door were sealed with a $0.33 \times 7.6-\mathrm{cm}$ piece of white rubber tape (3M brand; Home Hardware). Two Jay-Bee toggle clamps (JBT FA240; Acklands Grainger, Penticton, BC, Canada) were installed on each of the four sides of the chamber. Each of four chambers was fitted with an evaporator. Each evaporator was custom made from an aluminum rod $(38 \mathrm{~mm}$ diameter $\times 76 \mathrm{~mm}$ length) milled to hold $62 \mathrm{~mL}$ of liquid. This evaporator was drilled to fit a $9.5-\mathrm{mm}$ diameter $150-\mathrm{W}$ cartridge heater (CIR-2021-120V; Omega Engineering). Each chamber had a small hatch $(21.5 \times$ $31.5 \mathrm{~cm}$ ) through which water or AA was added to the evaporator. The hatch was secured using four Jay-Bee toggle clamps. A 115-mm 115-V 105 CFM tube axial fan (Model CFA11512038HS) was positioned in front of the evaporator to direct airflow over the device and circulate the air-acid mixture.

\section{Fumigation procedures}

Determining an effective acetic acid vapor dose to kill diapausing codling moth larvae. The objective of this experiment was to identify a dose of AA vapor that would cause $100 \%$ mortality $\left(\mathrm{LD}_{100}\right)$ of diapausing codling moth larvae. Fifty test larvae were placed on the floor of each of four identical 23-L chambers. Relative humidity in each chamber was adjusted to $60 \%$ to $70 \%$ by evaporating sterile distilled water before applying fumigation treatments. The same volume of water was added to each chamber. The control chamber was fitted with a dual-sensor relative humiditytemperature probe (Model ST-616CT; Alaron Instruments, Newmarket, ON, Canada) to monitor temperature and humidity during the fumigation. This probe could not be used in treatment chambers because AA corrodes the sensor and affects its operation. The assumption is that temperature and humidity conditions in the treatment chamber were the same as the control chamber. Control and AA treatments were randomly assigned to each chamber. Heating elements in control and treatment chambers were activated simultaneously. In each treatment chamber, an initial amount (Table 1) of 99.5\% glacial AA (Alphachem Ltd., Mississauga, ON, Canada) was evaporated from the small evaporator during the first minute of operation. Additional amounts of AA were added to each fumigation chamber at 20 and $200 \mathrm{~min}$, because it was important to have sufficient concentration of AA vapor acting on the insect over the duration of the treatment (Bond, 1984). AA concentrations $\left(\mathrm{mg} \cdot \mathrm{L}^{-1}\right)$ were monitored throughout experiments by withdrawing samples of air from the chamber headspace using a $1 \mathrm{~mL}$ gastight syringe immediately after the AA was vaporized and at regular intervals (5 to $10 \mathrm{~min}$ ) during the first 5 and last $3 \mathrm{~h}$ of fumigation. The 1-mL gas samples were injected into a Buck Model 910 gas chromatograph (GC) (Questron Technologies Corp., Mississauga, $\mathrm{ON}$, Canada) fitted with a flame ionization detector and fused silica capillary column (Zebron ZB-FFAP; Phenomenex, Torrance, CA). Cumulative exposure to AA in ppm-h was calculated by multiplying the concentration $(\mathrm{ppm})$ of $\mathrm{AA} \times$ the hours of fumigation (Bond, 1984; Luvisi et al., 1992). After fumigation, all chambers were placed in a fume hood and the lid opened and vented for $15 \mathrm{~min}$. All larvae were removed from each chamber, placed in separate screened $739-\mathrm{mL}$ plastic containers (GladWare ${ }^{\circledR}$; Glad Products Company, Oakland, CA), and transferred to a $20^{\circ} \mathrm{C}$ environmental chamber where they were held under a 16:8-h light:dark photoperiod. Starting $10 \mathrm{~d}$ after fumigation, all larvae were examined daily and the numbers of moths that had emerged were recorded. After $50 \mathrm{~d}$, all cocoons were opened and examined for any remaining live insects. Larvae were considered to be dead if they were dry and hard.

Fumigation treatment of diapausing codling moth in scale bins in 1- $m^{3}$ chambers. The fumigation procedure in $1-\mathrm{m}^{3}$ chambers was similar to that used with the 23-L chambers with the exception that it took $5 \mathrm{~min}$ to evaporate the AA. Air samples were collected from treatment chambers using a vacuum pump (Doerr Electric Corp., Cedarburg, WI), which drew headspace air into a 250-mL sampling bulb (Mandel Scientific, Guelph, ON, Canada). A 1-mL gas sample was taken from this bulb and injected into the GC.

Fifteen diapausing larvae were placed on the bottom of each of the four scale plastic $(48 \times$ $33 \times 29 \mathrm{~cm})$ or wooden bins $(61 \times 48.3 \times 27.3$ $\mathrm{cm})$ in each chamber. The 1:21st scale plastic bins were made of high-density polyethylene (Thunderbird Plastics Ltd., Burnaby, BC, Canada). The 1:12th scale wooden bins described by Gaunce et al. (1981) were used to mimic bins used in the British Columbia fruit industry. Four bins were stacked two deep and two high in each chamber and relative humidity was adjusted to $60 \%$ to $70 \%$ by evaporating $60 \mathrm{~mL}$ of sterile distilled water. The control chambers containing either four wooden or four plastic bins did not receive any AA. Thirty milliliters of glacial AA was evaporated in each of the test chambers. An additional 15 and $10 \mathrm{~mL}$ of AA were similarly added and evaporated at 30 and 210 min after initiation in each treatment chamber, respectively. No additional glacial AA was added during the remaining $24 \mathrm{~h}$. All fumigations were conducted at 26 to $28{ }^{\circ} \mathrm{C}$ and ambient atmospheric pressure. Treatments were randomly assigned to each chamber and replicated four times. After fumigation, all chambers were vented for $20 \mathrm{~min}$. To determine if there were any differences in mortality at different locations within each chamber, larvae from each bin within a chamber were held in separate screened $739-\mathrm{mL}$ plastic containers until moth emergence.

Maintenance of acetic acid levels. Our observation of low cumulative ppm-h of AA in the chambers containing scale wooden bins led to a fumigation study in which we monitored and attempted to maintain AA levels in an empty $1-\mathrm{m}^{3}$ chamber, a $1-\mathrm{m}^{3}$ chamber with six scale plastic bins, and a $1-\mathrm{m}^{3}$ chamber with four scale wooden bins for $24 \mathrm{~h}$. At the start of the fumigation, $20 \mathrm{~mL}$ of $\mathrm{AA}$ was added to each chamber. In the chamber containing scale wooden bins, an additional $10 \mathrm{~mL}$ of AA was added at 20 and $50 \mathrm{~min}$ followed by two $15-\mathrm{mL}$ injections at 70 and $110 \mathrm{~min}$. The chamber with wooden bins received $70 \mathrm{~mL}$ of AA in total. Fumigation treatments ended at $1300 \mathrm{~min}$.

Table 1. Volumes of glacial acetic acid (AA) and times it was injected into 23-L fumigation chambers and the cumulative exposure rates $(\mathrm{ppm}-\mathrm{h})$ for the different fumigation treatments used to determine an effective concentration required to kill diapausing codling moth larvae.

\begin{tabular}{lcccc}
\hline & \multicolumn{3}{c}{ The amount of AA $(\mu \mathrm{L})$ injected at each time interval per treatment } \\
\cline { 2 - 5 } Time $(\mathrm{T})$ acetic acid was added & Control & Treatment 1 & Treatment 2 & Treatment 3 \\
\hline $\mathrm{T}=-1 \mathrm{~min}$ & 0 & 220 & 440 & 660 \\
$\mathrm{~T}=20 \mathrm{~min}$ & 0 & 110 & 220 & 330 \\
$\mathrm{~T}=200 \mathrm{~min}$ & 0 & 55 & 110 & 220 \\
Total amount of AA added $(\mu \mathrm{L})$ & 0 & 385 & 770 & 1210 \\
Mean $( \pm \mathrm{sE})$ cumulative $\mathrm{ppm}-\mathrm{h}^{\mathrm{z}}$ & 0 & $61,940 \pm 4,544$ & $117,360 \pm 15,923$ & $174,823 \pm 9,319$ \\
\hline
\end{tabular}

${ }^{\mathrm{z}}$ Cumulative ppm-h was calculated by multiplying the concentration by time (ppm-h) and then adding up

all of the ppm-h over the duration of the fumigation. 


\section{Statistical analyses}

Larval mortality and adult emergence data were analyzed using a split-plot analysis of variance (ANOVA) in which the main-plot factor was bin type (wooden or plastic) and fumigation treatment was the subplot factor. All percentage data for codling moth mortality and adult emergence were arcsine-transformed before analysis. Treatment means were compared using Tukey's Studentized range test. A two-way ANOVA was used to determine the impact of cardboard weight on the treatment effect on codling moth mortality (SAS Institute, Inc., Cary, NC). All values throughout the test are presented as value $\pm \mathrm{SE}$.

\section{Results and Discussion}

Determining an effective acetic acid vapor dose to kill diapausing codling moth larvae

When the AA was vaporized in the three treatment chambers, there was an immediate decline in the concentration $\left(\mathrm{mg} \cdot \mathrm{L}^{-1}\right)$ of the AA vapor (Fig. 1). The concentration peaked after the addition of AA at 20 min followed by a slower decline in concentration. At 200 min, an additional amount of AA was vaporized and again the concentration slowly declined over the remaining duration of the fumigation. Randall and Sholberg (2007) observed a similar decline in AA concentration when cocooned codling moth larvae were fumigated with AA while being held in 29.6-mL plastic solo cups (Solo Cup Company, Highland Park, IL). The decline in the AA concentration during the first $20 \mathrm{~min}$ and the decline after the addition of AA at the 20 - and 200-min points are probably the result of the absorption of AA vapor by the insects. This rapid decline in $\mathrm{AA}$ concentration suggests that AA is diffusing into insects rather than being removed through active respiration of the insects. We calculated that the cumulative ppm-h of AA exposure for Treatments 1, 2, and 3 were $61,940 \pm 4,544,117,360 \pm 15,923$, and $174,823 \pm 9,319 \mathrm{ppm}-\mathrm{h}$, respectively. AA vapor had a significant impact on the mean percentages of codling moth adult emergence $\left(\mathrm{F}_{3,9}=97.4, P<0.0001\right)$ (Fig. 2). Treatment 1 was the only exposure rate that did not significantly decrease codling moth emergence below that of the control. Increasing the cumulative AA exposure to $174,823 \pm 9,319$ ppm-h caused $100 \%$ mortality of larvae and this rate was chosen for the subsequent scale bin trial. The total weight of the cardboard holding all larvae was not significantly different $(P>0.05)$ between the treatments or replicates.

\section{Bin fumigation}

Impact on diapausing codling moth larvae. The same initial decline in the concentration of AA vapor that was observed in Expt. 1 was also observed in the chambers containing the wooden or plastic bins (Fig. 3). However, there was a much lower concentration peak in the chamber containing the wooded bins. After the addition of AA, the peak concentration in the chamber with wooden bins did not reach the same level as in the chamber

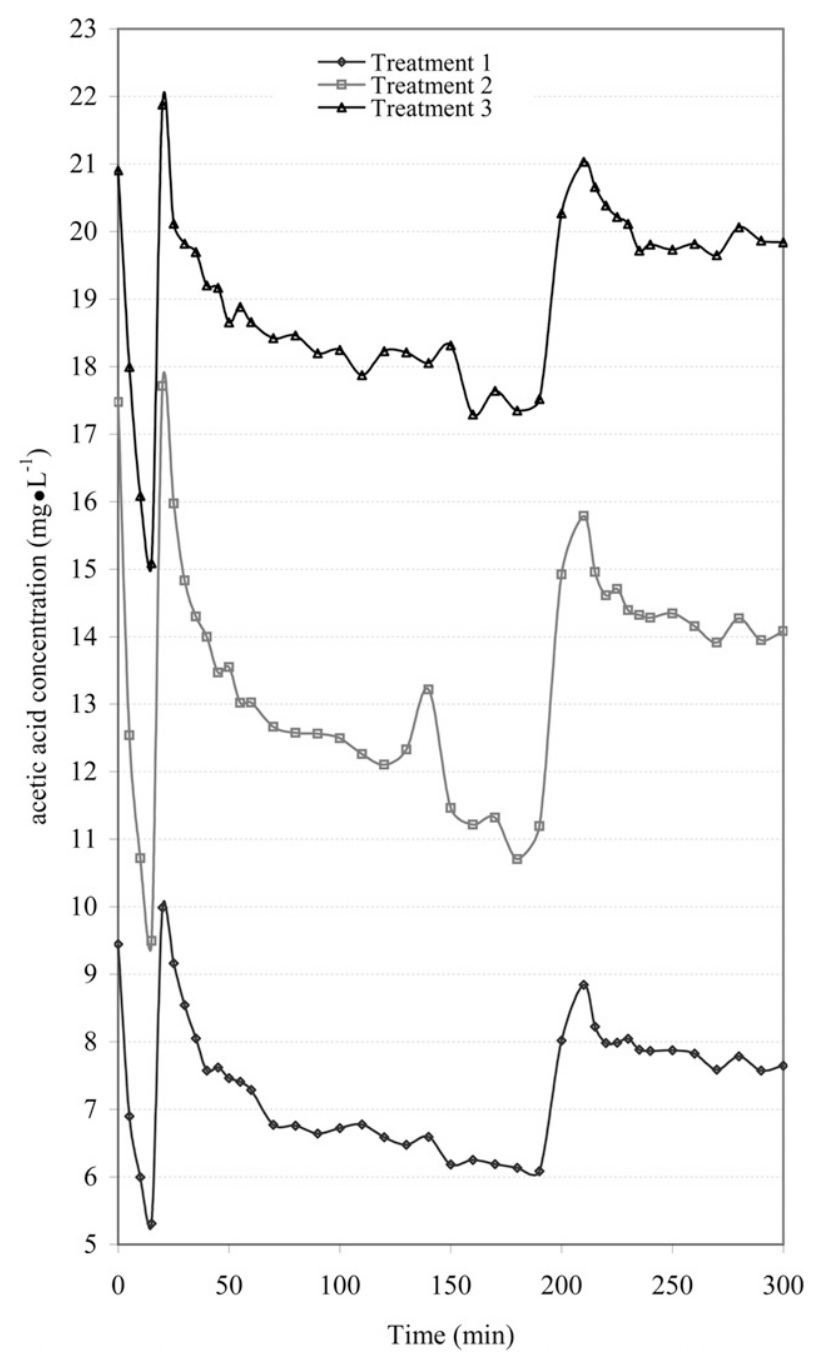

Fig. 1. The concentration of acetic acid (AA) $\left(\mathrm{mg} \cdot \mathrm{L}^{-1}\right)$ vapor in the headspace of 23 - $\mathrm{L}$ chambers containing diapausing codling moth larvae in cardboard after injection of an initial 220, 440, and $660 \mu \mathrm{L}$ AA for Treatments 1 to 3 , respectively (Table 1). There was an immediate decline in the amount of AA vapor in the first $20 \mathrm{~min}$ followed by a less rapid decline in vapor over the next $200 \mathrm{~min}$. This decline in the amount of AA vapor is the result of absorption of the AA by the insects and the cardboard. Only the first $300 \mathrm{~min}$ of the treatment time is shown.

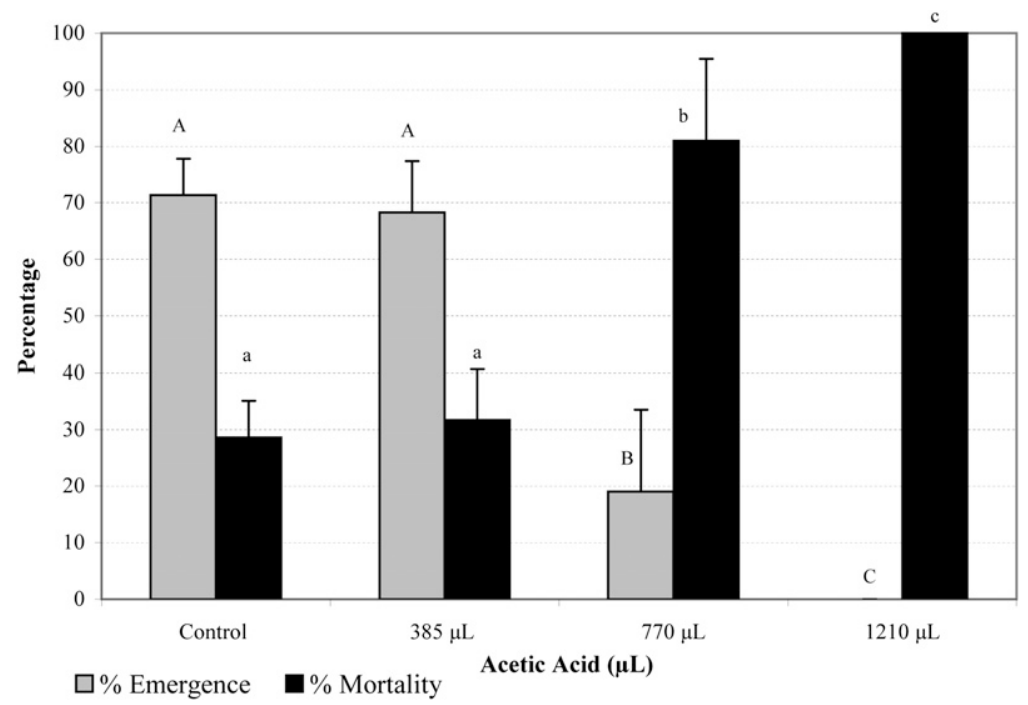

Fig. 2. Mean ( $\pm \mathrm{SE}$ ) percent mortality of diapausing codling moth larvae and subsequent emergence after fumigating larvae in 23-L chambers with different quantities of acetic acid (AA) (Table 1). $\mathrm{N}=50$ larvae replicated four times. Similarly shaded bars with the same letter superscript are not significantly different as determined by Tukey's Studentized range test $(\alpha=0.05)$. 
containing plastic bins. The concentration in the chamber with wooden bins rapidly declined to $2.2 \mathrm{mg} \cdot \mathrm{L}^{-1}$ by $400 \mathrm{~min}$ and by the end of the treatment period, it was down to 0.6 $\mathrm{mg} \cdot \mathrm{L}^{-1}$. The concentration of AA vapor in the headspace of chambers containing plastic bins peaked close to $21 \mathrm{mg} \cdot \mathrm{L}^{-1}$ after the third addition of AA and then declined slowly to $14.5 \mathrm{mg} \cdot \mathrm{L}^{-1}$ by the end of the fumigation (Fig. 3). In this experiment, the mean total exposure to AA vapor in the chambers with plastic bins was calculated to be $171,073 \pm$ $14,133 \mathrm{ppm}-\mathrm{h}$. In contrast, the total concentration of AA in the chamber containing wooden bins was only $19,453 \pm 2,376 \mathrm{ppm}-\mathrm{h}$. In the previous experiment, this exposure rate was determined to be too low to have an effect on larval mortality or codling moth emergence.

Codling moth emergence after treatment with AA fumigation in wooden bins was not significantly different $(P>0.05)$ from those

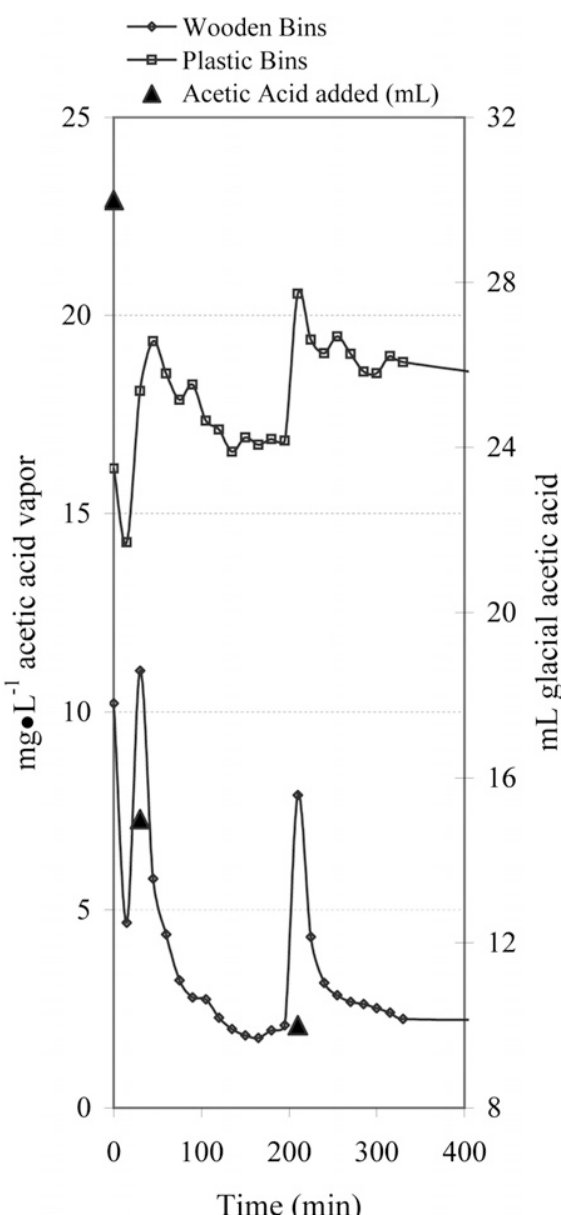

Fig. 3. Acetic acid (AA) vapor $\left(\mathrm{mg} \cdot \mathrm{L}^{-1}\right)$ within the fumigation chamber headspace for the first 400 min of the 24-h fumigation of scale wood and plastic bins. There was an initial rapid decline in the amount of AA vapor in both chambers. This is the result of the absorption of the AA vapor by the insect tissue and the cardboard containing the larvae. The concentration of AA in the chamber with the wooden bins does not obtain the same level as in the chamber with plastic bins and the concentration declines faster. This is possibly the result of the absorption of the AA vapor by the wood. of codling moth removed from untreated wooden and plastic control bins (Table 2). In contrast, $100 \%$ of the codling moth larvae placed in plastic bins died after fumigation with AA. During fumigation of wooden bins, not only are the insects and cardboard absorbing the AA, but it appears that the wooden bins themselves absorb AA in a very rapid manner. This rapid decrease in AA prevents the atmospheric concentration of AA from ever reaching the levels required to successfully kill diapausing codling moth larvae present in wooden bins.

Maintenance of acetic acid headspace concentrations above wooden and plastic bins. The headspace concentration of AA vapor in both an empty chamber and the chamber containing plastic bins remained constant throughout the duration of the fumigation (Fig. 4). In an empty chamber, and the chamber with plastic bins, the AA vapor concentrations after a single injection of $20 \mathrm{~mL}$ of AA decreased from a high of $24 \mathrm{mg} \cdot \mathrm{L}^{-1}$ at the start to a low of $17 \mathrm{mg} \cdot \mathrm{L}^{-1}$ after $1300 \mathrm{~min}$ (Fig. 4). Unlike the previous experiments, when larvae were held in cardboard, there was no initial decline in the amount of AA vapor in the empty chamber or in the chamber containing the plastic bins. This supports the concept that the insects and possibility the cardboard are absorbing the AA and when the insect absorbs sufficient AA, it is killed. The total exposures to AA in an empty chamber and a chamber with plastic bins were calculated to be 173,309 and $175,855 \mathrm{ppm}-\mathrm{h}$, respectively. These values were similar to those needed to obtain $100 \%$ mortality of codling moth larvae in the previous experiments.

The average headspace concentration of AA vapor in the chamber containing four wooden bins peaked at $17.9 \mathrm{mg} \cdot \mathrm{L}^{-1}$ immediately after injection but declined rapidly thereafter. Subsequent injections of AA produced peaks in AA concentrations, but these were also followed by rapid decreases over the next 200 min (Fig. 2). At 1300 min after initiating the fumigation of wooden bins, the AA vapor concentration had decreased to $0.48 \mathrm{mg} \cdot \mathrm{L}^{-1}$. We calculated that the wooden bins received a total of $25,364 \mathrm{ppm}-\mathrm{h}$ of AA exposure. This exposure rate was seven times less than what we observed in the empty chambers or chambers containing plastic bins despite an increased number of injections and greater total amount of AA added to chambers with wooden bins $(70 \mathrm{~mL})$ compared with plastic bins $(20 \mathrm{~mL})$. The AA vapor concentrations in the empty chamber and the chamber containing plastic bins declined by $30 \%$ over the 21.7-h fumigation period, whereas in this same period, the concentrations in the chamber with wooden bins declined by $98 \%$. The absorption of AA vapor by wooden and plastic bins is significantly different. The rapid absorption of the AA in the chambers is the result of the wooden bins. A similar effect was previously reported when wooden bins were exposed to 1-methylcyclopropene (1-MCP), but the decline of 1-MCP by wood or cardboard was not as rapid (Calvo and Sozzi, 2009; Rodriguez-Perez et al., 2009; Vallejo and Beaudry, 2006). The exact mechanism by which AA vapor declines in chambers containing wooden bins is not known but potential explanations are that the AA is reacting with the moisture within the plywood, interacting with wood fibers, or is being absorbed into intercellular spaces. The humidity in the chamber at the start of the fumigation was $30 \%$ before adding water to increase the humidity to $60 \%$ to $70 \%$ and the equilibrium moisture content (EMC) of the plywood surface would increase from $6 \%$ to $11 \%$ to $13 \%$ (CertiWood $^{\mathrm{TM}}$ Technical Centre, 2009). The change of moisture content in wood is the result of the cell wall polymers attracting water vapor through hydrogen bonding (Rowell, 1983). Could the wood or the moisture in the wood be attracting the AA in a similar way? When wood is acetylated with acetic anhydride vapor, to improve the dimensional stability in humid conditions, it reacts with the cell walls forming covalently bonded acetyl groups and the byproduct of this process is AA (Larsson Brelid et al., 1999). This AA in the wood is virtually impossible to remove and imparts undesirable qualities such as the wood smells of AA, can cause acid hydrolysis of cellulose fibers and acid corrosion of metal fasteners that are used in the manufacturing of the wooded bins (Rowell, 1983). It is possible to remove the AA and unreacted acetic anhydride if the wood is heated to 120 to $130{ }^{\circ} \mathrm{C}$, which is above the boiling point of AA, and then a vacuum is applied. Any remaining AA is then removed by oven-drying (Larsson Brelid, 2002). The acetylation of wood decreased as the moisture content increased beyond an EMC of $3 \%$ to $5 \%$, and this was the result of the moisture of the wood reacting with the acetic anhydride to form AA (Tarkow et al., 1955). Therefore, it is possible that the AA vapor is being absorbed into the intercellular space and interacts with the moisture and possibly the cellulose in the wood. Because the

Table 2. The emergence of adult codling moth after a 24-h fumigation of diapausing larvae in plastic or wooden bins held in $1-\mathrm{m}^{3}$ chambers treated with $55 \mathrm{~mL}$ of $95 \%$ glacial acetic acid (AA) compared with emergence from untreated control larvae. ${ }^{2}$

\begin{tabular}{lccc}
\hline Bin type & $\begin{array}{c}\text { Fumigation } \\
\text { treatment }\end{array}$ & $\begin{array}{c}\text { Mean }( \pm \mathrm{SE}) \mathrm{AA} \\
\text { exposure ppm-h }\end{array}$ & $\begin{array}{c}\text { Mean }( \pm \mathrm{SE}) \text { percent } \\
\text { adult emergence }^{\mathrm{y}}\end{array}$ \\
\hline Plastic & AA & $171,073 \pm 14,133$ & $0.0 \pm 0.0 \mathrm{~b}$ \\
Wooden & Control & 0 & $85.3 \pm 2.3 \mathrm{a}$ \\
& AA & $19,453 \pm 2,376$ & $83.0 \pm 3.0 \mathrm{a}$ \\
& Control & 0 & $87.3 \pm 1.9 \mathrm{a}$ \\
\hline
\end{tabular}

${ }^{\mathrm{z}} \mathrm{N}=$ four replicates with 60 larvae in each replicate with each bin type.

${ }^{y}$ Means for a given bin type within a column followed by different letters are significantly different by twosample $t$ test $(P<0.05)$. 


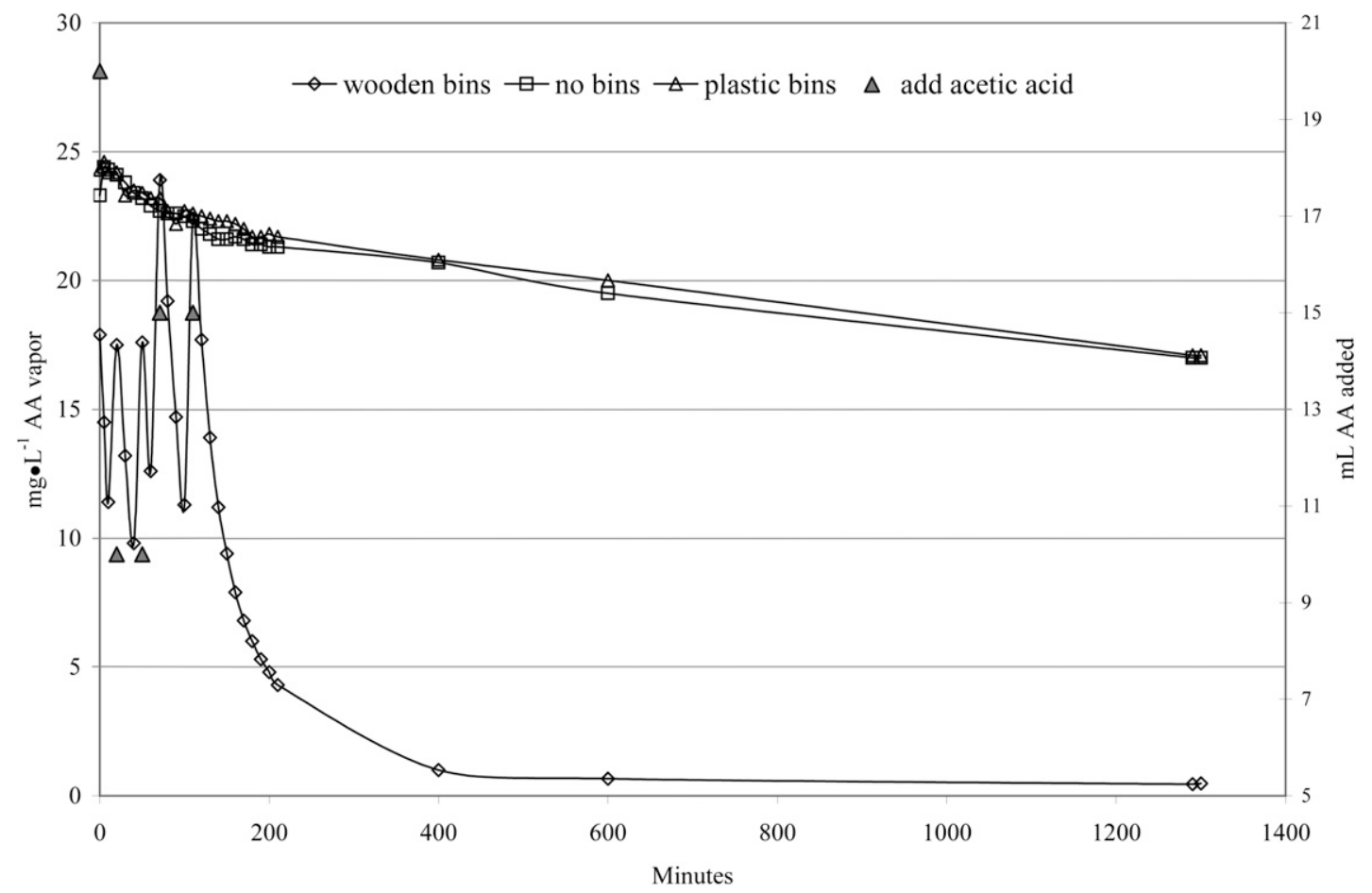

Fig. 4. Changes over time in the concentrations of acetic acid (AA) vapor $\left(\mathrm{mg} \cdot \mathrm{L}^{-1}\right)$ as measured within the headspace of an empty $1-\mathrm{m}^{3}$ fumigation chamber and similar chambers holding six 1:21 scale plastic or four 1:12 scale wooden bins that received a single 20-mL injection of AA (scale plastic bins) or multiple injections of varied amounts (scale wooden bins). There is not rapid decline of the AA vapor in the empty chamber or the one with the plastic bins.

AA is rapidly absorbed by the wooden bin, the concentration in the chamber is too low to affect the codling moth larvae mortality and this additional AA has a negative effect on the wood.

Attempts to kill codling moth larvae in empty wooden bins using a variety of techniques have met with varied success. Cossentine et al. (2004) found that a 20-d exposure to an atmosphere containing $13 \%$ carbon dioxide caused $75 \%$ mortality of diapausing codling moth larvae placed in wooden bins. Mortality of larvae using entomopathogenic nematodes was better, ranging from $80 \%$ to $90 \%$ (Cossentine et al., 2002; Lacey and Chauvin, 1999; Lacey et al., 2005). The most effective treatment appears to be submerging wooden bins in an $80^{\circ} \mathrm{C}$ hot water bath for $30 \mathrm{~s}$, from which less than $0.2 \%$ of the larvae survive (Hansen et al., 2006). Although AA vapor is clearly toxic to codling moth larvae, exposure to AA vapor when larvae are located in wooden bins was significantly less effective than any of the previously tested methods. Given that most of the British Columbia apple industry still relies on the use of wooden bins, fumigation with AA cannot currently be recommended as a practical method of disinfesting wooden bins of dispausing codling larvae. However, should the British Columbia apple industry ever choose to use plastic bins, as they have in Switzerland, Italy, and the United States (Waelti, 1992), then a fumigation treatment with glacial AA vapor could be recommended because it caused $100 \%$ mortality of diapausing larvae in plastic bins. This treatment, combined with the use of plastic bins, that harbor far fewer codling moth larvae than wooden bins (Higbee et al., 2001) could provide a useful strategy to augment areawide efforts to manage or eradicate codling moth in British Columbia (Judd and Gardiner, 2005). This method may eventually prove to be an economically viable strategy for preventing reintroduction of wild codling moth into designated areas of low pest prevalence.

\section{Literature Cited}

Bond, E.J. 1984. Manual of fumigation for insect control. FAO Plant Prod. Prot. Paper 54.

Calvo, G. and G. Sozzi. 2009. Effectiveness of 1MCP treatments on 'Bartlett' pears as influenced by the cooling method and the bin material. Postharvest Biol. Technol. 51:49-55.

CertiWood $^{\mathrm{TM}}$ Technical Centre. 2009. Plywood Design Fundamentals. 25 Aug. 2011. <http:// www.canply.org/pdf/main/plywood_designfund. $\mathrm{pdf}>$.

Cossentine, J.E., L.B.J. Jensen, and L. Moyls. 2002. Fruit bins washed with Steinernema carpocapsae (Rhabditida: Steinernematidae) to control Cydia pomonella (Lepidoptera: Tortricidae). Biocontrol Sci. Technol. 12:251-258.

Cossentine, J.E., P.L. Sholberg, L.B.J. Jensen, K.E. Bedford, and T.C. Shephard. 2004. Fumigation of empty fruit bins with carbon dioxide to control diapausing codling moth larvae and Penicillium expansum Link. Ex Thom spores. HortScience 39:429-432.

De Waal, J.Y., A.P. Malan, J. Levings, and M.F. Addison. 2010. Key elements in the successful control of diapausing codling moth, Cydia pomonella (Lepidoptera: Tortricidae) in wooden fruit bins with a South African isolate of Heterorhabditis zealandica (Rhabditida: Heterorhabditidae). Biocontrol Sci. Technol. 20: 489-502.

Gaunce, A.P., H.F. Madsen, and R.D. McMullen. 1981. Fumigation with methyl bromide to kill larvae and eggs of the codling moth in Lambert cherries. J. Econ. Entomol. 74:154-157.

Hansen, J.D., M.L. Heidt, and P.A. Anderson. 2006. Bin sterilization to prevent reintroduction of codling moth. J. Agr. Urban Entomol. 23:17-26.

Higbee, B.S., C.O. Calkins, and C.A. Temple. 1999. Larval infestation of harvest bins by codling moth. Good Fruit Grower 50:26-31.

Higbee, B.S., C.O. Calkins, and C.A. Temple. 2001. Overwintering of codling moth (Lepidoptera: Tortricidae) larvae in apple harvest bins and subsequent moth emergence. J. Econ. Entomol. 94:1511-1517.

Judd, G.J.R. and M.G.T. Gardiner. 2005. Towards eradication of codling moth in British Columbia by complimentary actions of mating disruption, tree-banding and sterile insect technique: Fiveyear study in organic orchards. Crop Prot. 24:718-733.

Judd, G.J.R., M.G.T. Gardiner, and D.R. Thomson. 1997. Control of codling moth in organicallymanaged apple orchards by combining pheromonemediated mating disruption, post-harvest fruit removal and tree banding. Entomol. Exp. Appl. 83:137-146.

Lacey, L.A. and R.L. Chauvin. 1999. Entomopathogenic nematodes for control of diapausing codling moth (Lepidoptera: Tortricidae) in fruit bins. J. Econ. Entomol. 92:104-109.

Lacey, L.A., L.G. Neven, H.L. Headrick, and R. Fritts, Jr. 2005. Factors affecting entomopathogenic nematodes (Steinernmatidae) for control of overwintering codling moth (Lepidoptera: Tortricidae) in fruit bins. J. Econ. Entomol. 98: 1863-1869.

Lacey, L.A. and T.R. Unruh. 1998. Entomopathogenic nematodes for control of codling moth, Cydia pomonella (Lepidoptera: Tortricidae): Effect of nematode species, concentration, temperature and humidity. Biol. Control 13:190-197.

Larsson Brelid, P. 2002. The influence of posttreatments on acetyl content for removal of 
chemicals after acetylation. Holz als Rod- und Wekstoff 60:92-95.

Larsson Brelid, P., R. Simonson, and P.O. Risman. 1999. Acetylation of solid wood using microwave heating. Holz als Rod- und Wekstoff 57:259-263.

Luvisi, D.A., H.H. Shorey, J.L. Smilanick, J.F. Thompson, B.H. Gump, and J. Knutson. 1992 Sulfur dioxide fumigation of table grapes. Division of Agriculture and Natural Resources, University of California, Bulletin, 1932, Oakland, CA.

Moyls, A.L., P.L. Sholberg, and A.P. Gaunce. 1996. Modified-atmosphere packaging of grapes and strawberries fumigated with acetic acid. HortScience 31:414-416.

Newcomer, E.J. 1936. Orchard sanitation for control of codling moth. Better Fruit 30:5.

Proverbs, M.D. and J.R. Newton. 1975. Codling moth control by sterile insect release: Importation of fruit and fruit containers as a source of reinfestation. J. Entomol. Soc. B.C. 72:6-9.

Randall, P. and P. Sholberg. 2007. Acetic acid vapors to decontaminate bins and storage rooms. In: 2007 Apple Crop Protection Research ReviewWashington Tree Fruit Research Commission. 31 Aug. 2011. <http://jenny.tfrec.wsu.edu/wtfrc/
PDFfinalReports/2007FinalReports/Randall. pdf>.

Rodriguez-Perez, L., B. Harte, R. Auras, G. Burgess, and R.M. Beaudry. 2009. Measurement and prediction of the concentration of 1-methylcyclopropene in treatment chambers containing different packaging materials. J. Sci. Food Agr. 89:2581-2587.

Rowell, R.M. 1983. Chemical modification of wood. Forest Prod Abstr. 6:363-382.

Sholberg, P. 2009. Control of postharvest decay by fumigation with acetic acid or plant volatile compounds. Fresh Produce 3(Special Issue 1): 80-86.

Sholberg, P.L., D.A. Gaudet, B. Puchalski, and P. Randall. 2006. Control of common bunt (Tilletia tritici and T. laevis) of wheat (Triticum aestivum cv. 'Laura') by fumigation with acetic acid vapour. Can. J. Plant Sci. 86 : 839-843.

Sholberg, P.L. and A.P. Gaunce. 1995. Fumigation of fruit with acetic acid to prevent postharvest decay. HortScience 30:1271-1275.

Sholberg, P.L. and A.P. Gaunce. 1996. Fumigation of stonefruit with acetic acid to control postharvest decay. Crop Prot. 15:681-686.
Sholberg, P.L., P. Haag, R. Hocking, and K. Bedford. 2000. The use of vinegar vapor to reduce postharvest decay of harvested fruit. HortScience 35:898-903.

Sholberg, P.L., P. Randall, and C.R. Hampson. 2005. Acetic acid fumigation of apple rootstocks and tree fruit scion wood to remove external microflora and potential plant pathogens. HortTechnology 15:591-596.

Sholberg, P.L., T. Shephard, P. Randall, and L. Moyls. 2004. Use of measured concentrations of acetic acid vapour to control postharvest decay in d'Anjou pears. Postharvest Biol. Technol. 32:89-98.

Tarkow, H., A.J. Stamm, and E.C.O. Erickson. 1955. Acetylated wood. Report, Forest Products Laboratory, USDA Forest Service No. 1593.

Vallejo, F. and R. Beaudry. 2006. Depletion of 1 MCP by 'non-target' materials from fruit storage faculties. Postharvest Biol. Technol. 40: 177-182.

Waelti, H. 1992. Should we use plastic bins? Tree Fruit Postharvest Journal 3:14-17. 18 June 2007. <http://postharvest.tfrec.wsu.edu/ pages/J3I4C/>. 